\title{
Characteristic electron microscopic findings in the skin of patients with fibromyalgia-preliminary study
}

\author{
Seong-Ho Kim • Dong Hoon Kim • Dong-Ho Oh • \\ Daniel J. Clauw
}

Published online: 19 December 2007

(C) Clinical Rheumatology 2007

\begin{abstract}
This blinded study was done to determine if there are any abnormal electron microscopic (EM) findings in the skin of fibromyalgia syndrome (FMS) patients, which might contribute to or be due to the increased pain sensitivity seen in this condition. Skin biopsy samples were obtained from 13 FMS patients and 5 control subjects. All tissues were prepared for EM examination by immediate prefixation in $2.5 \%$ glutaraldehyde for $2 \mathrm{~h}$ and postfixation in $1 \%$ osmium acid for $24 \mathrm{~h}$. Ultrathin sections on grids were stained by uranyl acetate and lead citrate. Biopsies were read by an individual without knowledge of participant status. Five skin biopsies from healthy controls showed relatively even distribution of variegated sized unmyelinated axons sheathed well by complicatedly folded Schwann cell membranes. In tissues
\end{abstract}

This article was published in Volume 27, Number 2 (2008) of Clinical Rheumatology but contained numerous errors throughout. In order to facilitate the comprehension of the article, a corrected version is published here in its entirely.

The online version of the original article can be found at: http://dx.doi. org/10.1007/s10067-007-0739-2.

S.-H. Kim $(\bowtie) \cdot$ D. H. Kim

Dongguk University College of Medicine,

Gyeongju, South Korea

e-mail: junjan@dongguk.ac.kr

D. H. Kim

e-mail: moonebal@empal.com

D.-H. Oh

Pohang St. Mary's Hospital,

Pohang, South Korea

e-mail: rheumatis@hanmail.net

D. J. Clauw

University of Michigan Chronic Pain

and Fatigue Research Center,

Ann Arbor, MI, USA

e-mail: dclauw@med.umich.edu from 9/13 FMS patients, unmyelinated Schwann cells were noted to be ballooned, whereas this finding was not noted in any controls $(p=0.029)$. Axons in most patients trended towards being localized in the periphery of the unmyelinated Schwann cell sheaths $(p=0.002)$. Particularly, peripheral localization of axon in the unmyelinated Schwann cell sheath had a strong relationship with ballooning of Schwann cell $(p=0.042)$, simplified folding of Schwann cell sheath $(p=0.039)$ and smaller axon $(p=0.034)$. Myelinated nerve fibers were unremarkable. The EM findings seen in the skin of FMS patients show unusual patterns of unmyelinated nerve fibers as well as associated Schwann cells. If these findings are replicated in a larger study, these abnormalities may contribute to, or be due to, the lower pain threshold seen in FMS patients.

Keywords Electron microscope · Fibromyalgia - Skin . Unmyelinated

\section{Introduction}

Fibromyalgia syndrome (FMS) is a chronic, generalized pain condition with diffuse tenderness on physical examination, and is often accompanied by a number of associated symptoms such as sleep disturbance, fatigue, headache, irritable bowel syndrome, and mood disorders $[1,2]$. The mechanisms responsible for symptom expression in FMS are complex. The most consistently detected objective abnormalities in FMS involve pain-processing systems [3, 4]. Psychophysical studies, functional neuroimaging, and many other lines of research have suggested that FMS patients display augmented central pain processing [5]. In addition to neurobiologic mechanisms, psychologic and behavioral factors also play a role in symptom expression in many patients [5]. 
There are many reasons that the augmented pain processing in FMS has been felt to be primarily due to abnormalities in central pain processing. First, the low pain threshold in FMS extends throughout the body, and is not just confined to areas such as tender points, or tissues that have underlying muscle [6]. Moreover, the fact that individuals with FMS are not just more sensitive to pressure but also to heat, noise, and auditory stimuli suggests a diffuse central nervous system defect in sensory processing. Second, FMS shares significant demographic, physiologic, and therapeutic response profiles with a number of other pain syndromes, especially visceral syndromes such as irritable bowel syndrome, interstitial cystitis, and noncardiac chest pain [7]. Finally, most previous studies of the peripheral tissues of FMS, especially the skeletal muscle, had been unremarkable [8]. However, Sprott's electron microscopic (EM) findings suggest that patients with FMS are characterized by abnormalities in muscle tissue that include increased DNA fragmentation and changes in the number and size of mitochondria [9].

Recently, investigators have questioned whether the peripheral nerves may be abnormal in FMS, either because these abnormalities contribute to the pain sensitivity, or alternatively are due to the decreased pain threshold [1015]. For example, Kim et al. reported that N-methyl-Daspartate receptors subtype $2 \mathrm{D}$ expression was increased in the skin of patients with FMS versus controls and suggested that this could be indicative of a more generalized increase in other peripheral nerves [10]. Other investigators noted differences in the amino acid composition of skin proteins in FMS compared with controls, and found that collagen packing in the endoneurium might be less dense [11].

Several other studies support the notion that there may be increased neurogenic inflammation in patients with FMS, presumably reflective of increased activity of polymodal nociceptors of unmyelinated primary afferent nerves [12-15]. FMS skin biopsies have significantly higher IgG deposits in the dermis and vessel walls, as well as a higher mean number of mast cells [13]. The detection of IL-1, IL6 , and tumor necrosis factor- $\alpha$, and the finding of highly ordered cuffs of collagen around the terminal nerve fibers in skin of patients with FMS by EM examination also support the presence of neurogenic inflammation $[14,15]$.

The aim of the present study was to investigate whether there were characteristic EM findings in skin from FMS patients when compared with skin from control subjects who were matched for age and gender.

\section{Materials and methods}

Patients were diagnosed as having FMS according to the American College of Rheumatology (ACR) criteria [1]. Skin biopsies from non-tender left deltoid region of 13 patients and 5 healthy 'age- and sex-matched' controls (Table 1) were performed after informed consent was obtained from participants. Table 2 shows the demographic characteristics of the patients with FMS. All work was previously approved by the institutional review board of Dongguk University College of Medicine.

All tissues were prepared for EM examination by immediate prefixation in $2.5 \%$ glutaraldehyde $(0.1 \mathrm{M}$ phosphate buffer, $\mathrm{pH} 7.3)$ for $2 \mathrm{~h}$ and postfixation in $1 \%$ osmium acid $(0.1 \mathrm{M}$ phosphate buffer, $\mathrm{pH} 7.3$ ) for $24 \mathrm{~h}$. After washed in buffer solution, fixed tissues were dehydrated through graded ethanol, and embedded in Epon. Ultrathin sections on grids were stained by uranyl acetate and lead citrate. Hitachi H-7500 and H-7100 transmission electron microscopes (Hitachi, Ibaraki, Japan) were used. Samples were read by two pathologists blinded to the study design. Unmyelinated fibers were scrutinized about sizes of axon and Schwann cell, the degree of the sheath folding, location of axons in sheath, and so on. Each pathologist was asked to assign a score of $0,1,2$ for criteria including Schwann cell ballooning, axon in center, collagen crosslinks, etc. (Table 3). They showed 100\% agreement regarding the characteristics of each sample (kappa=1).

Statistical analysis was performed using SPSS for Windows (version 11.0; SPSS, Chicago, IL). Fisher's exact test was used to determine $P$ values in all categorical data. Mann-Whitney $U$ test was used to determine $P$ value in age comparison of patients and controls. The associations were analyzed by means of Spearman's rank correlation test. A $P$ value of 0.05 was considered significant.

\section{Results}

The skin appeared normal on light microscopic findings in all specimens from patients and controls. The five skin biopsies from controls showed relatively even distribution of variegated sized axons sheathed well by complicatedly folded Schwann cell membranes (Fig. 1a,b).

In biopsied skins from 13 patients with FMS, most unmyelinated Schwann cells in 9 cases were ballooned ( $p=$ 0.029). Axons in most patients trended to be peripheralized in their unmyelinated Schwann cell sheaths $(p=0.002)$. Folding structures of the Schwann cell sheathed individual

Table 1 Characteristics of the control subjects and patients with fibromyalgia

\begin{tabular}{llll} 
& $\begin{array}{l}\text { Fibromyalgia } \\
\text { patients }(n=13)\end{array}$ & $\begin{array}{l}\text { Normal control } \\
(n=5)\end{array}$ & $P$ values \\
\hline Age, mean \pm SD (years) & $47.4 \pm 10.9$ & $50.0 \pm 14.1$ & $0.961^{\mathrm{a}}$ \\
Sex, female/male & $10: 3$ & $3: 2$ & $0.583^{\mathrm{b}}$ \\
\hline
\end{tabular}

${ }^{a}$ By Mann-Whitney $U$ test

${ }^{\mathrm{b}}$ By Fisher's exact test 
Table 2 Demographic characteristics of the patients with fibromyalgia

\begin{tabular}{|c|c|c|c|}
\hline $\begin{array}{l}\text { Patients/ } \\
\text { age/sex }\end{array}$ & $\begin{array}{l}\text { Disease } \\
\text { duration at time } \\
\text { of biosy, years }\end{array}$ & Concurrent medication & $\begin{array}{l}\text { Confounding } \\
\text { diseases }\end{array}$ \\
\hline $1 / 58 / \mathrm{F}$ & 0.5 & $\mathrm{G}, \mathrm{E}$ & \\
\hline $2 / 52 / \mathrm{F}$ & 10 & $\begin{array}{l}\text { G, A, AP, C, ALP, } \\
\text { T, GL, M }\end{array}$ & Diabetes \\
\hline $3 / 42 / F$ & 4 & AM, TR, ALP, R, L & Hypertension \\
\hline $4 / 49 / F$ & 5 & $\mathrm{G}, \mathrm{A}, \mathrm{TR}, \mathrm{ALP}$ & Hypertension \\
\hline $5 / 47 / \mathrm{F}$ & 6 & $\mathrm{G}, \mathrm{A}$ & \\
\hline $6 / 41 / F$ & 5 & $\mathrm{G}, \mathrm{E}$ & \\
\hline $7 / 53 / \mathrm{M}$ & 3 & $\mathrm{CM}$ & \\
\hline $8 / 73 / \mathrm{M}$ & 2 & G, TR, D & Diabetes \\
\hline $9 / 46 / \mathrm{F}$ & 0.5 & & \\
\hline $10 / 40 / \mathrm{F}$ & 0.5 & $\mathrm{P}$ & \\
\hline $11 / 26 / \mathrm{M}$ & 3 & $\mathrm{AM}, \mathrm{AP}+\mathrm{TR}$ & \\
\hline $12 / 45 / \mathrm{F}$ & 3 & AM, EM, ET & \\
\hline $13 / 44 / \mathrm{F}$ & 0.7 & E, ET & \\
\hline
\end{tabular}

$G$ Gabapentin, $E$ Eperisone HCL, $A$ Aceclofenac, $A P$ Acetaminophen, $C$ Carbanazepine, $A L P$ Alprazolam, $T$ Triazolam, $G L$ Gliclazide, $M$ Metformin, AM Amitriptyline HCL, TR Tramadol HCL, $R$ Ramipril, $L$ Lercanidipine HCL, $C M$ Clematis mandshurica etc., $D$ Diacerein, $P$ Piroxicam, EM Etodolac micronized, ET Etizolam

axons were simplified definitely in three cases. Peripheralization of axon in the unmyelinated Schwann cell sheath occurred in association with ballooning of Schwann cell $(p=$ 0.042), simplified folding of Schwann cell sheath $(p=0.039)$ and smaller axon $(p=0.034)$. Collagen fibrils filling in endoneurium seem to be noted in similar frequency in FMS $(X / Y)$ and controls $(X / Y)$. Splitting of perineurium was observed in relatively equal frequency in FMS $(X / Y)$ and controls $(X / Y)$. Three controls and four patients revealed collagen replacement of axon (Fig. 1c-f). Collagen crosslinks were detected in two cases of FMS but no controls (Fig. 1i).

Because of these findings, we performed a second skin biopsy in the forearm of one patient to determine if the changes seen above were present in both a classic tender point (the lateral epicondyle area) and non-tender point (the deltoid region). These two sites showed qualitatively similar findings, though the unmyelinated Schwann cells from the tender area were more ballooned than those from the non-tender area (Fig. 1g and h).

The skin otherwise appeared normal on EM examination in all specimens from patients and controls, especially in myelinated fibers.

\section{Discussion}

This is the first study to note characteristic EM findings of unmyelinated nerve fibers in the skin of patients with FMS. The most striking finding was that most unmyelinated Schwann cells in FMS skin were ballooned compared with controls, and that the axons trended to be peripheralized in

Table 3 Scores of the two pathologists for each criteria

\begin{tabular}{|c|c|c|c|c|c|c|c|c|}
\hline & $\begin{array}{l}\text { Ballooning } \\
\text { of SC }\end{array}$ & $\begin{array}{l}\text { Axon in } \\
\text { center }\end{array}$ & $\begin{array}{l}\text { Simplified folding } \\
\text { of SC membrane }\end{array}$ & $\begin{array}{l}\text { Replacement } \\
\text { by collagen }\end{array}$ & $\begin{array}{l}\text { Hydropic degeneration } \\
\text { of axon }\end{array}$ & $\begin{array}{l}\text { Small } \\
\text { axon }\end{array}$ & $\begin{array}{l}\text { Increased } \\
\text { mitochondria }\end{array}$ & $\begin{array}{l}\text { Collagen } \\
\text { crosslink }\end{array}$ \\
\hline \multicolumn{9}{|c|}{ Patient } \\
\hline 1 & $1 / 1$ & $1 / 1$ & $0 / 0$ & $0 / 0$ & $0 / 0$ & $1 / 1$ & $0 / 0$ & $0 / 0$ \\
\hline 2 & $0 / 0$ & $1 / 1$ & $0 / 0$ & $1 / 1$ & $1 / 1$ & $1 / 1$ & $0 / 0$ & $1 / 1$ \\
\hline 3 & $1 / 1$ & $1 / 1$ & $0 / 0$ & $1 / 1$ & $0 / 0$ & $1 / 1$ & $0 / 0$ & $0 / 0$ \\
\hline 4 & $1 / 1$ & $1 / 1$ & $0 / 0$ & $0 / 0$ & $0 / 0$ & $1 / 1$ & $0 / 0$ & $0 / 0$ \\
\hline 5 & $0 / 0$ & $1 / 1$ & $0 / 0$ & $0 / 0$ & $1 / 1$ & $1 / 1$ & $1 / 1$ & $1 / 1$ \\
\hline 6 & $0 / 0$ & $1 / 1$ & $0 / 0$ & $0 / 0$ & $0 / 0$ & $0 / 0$ & $0 / 0$ & $0 / 0$ \\
\hline 7 & $0 / 0$ & $1 / 1$ & $1 / 1$ & $0 / 0$ & $0 / 0$ & $0 / 0$ & $0 / 0$ & $0 / 0$ \\
\hline 8 & $1 / 1$ & $0 / 0$ & $1 / 1$ & $0 / 0$ & $1 / 1$ & $1 / 1$ & $0 / 0$ & $0 / 0$ \\
\hline 9 & $1 / 1$ & $0 / 0$ & $1 / 1$ & $0 / 0$ & $0 / 0$ & $1 / 1$ & $0 / 0$ & $0 / 0$ \\
\hline 10 & $1 / 1$ & $1 / 1$ & $0 / 0$ & $1 / 1$ & $0 / 0$ & $1 / 1$ & $0 / 0$ & $0 / 0$ \\
\hline 11 & $1 / 1$ & $1 / 1$ & $0 / 0$ & $1 / 1$ & $0 / 0$ & $0 / 0$ & $0 / 0$ & $0 / 0$ \\
\hline 12 & $1 / 1$ & $1 / 1$ & $0 / 0$ & $1 / 1$ & $0 / 0$ & $1 / 1$ & $0 / 0$ & $0 / 0$ \\
\hline 13 & $1 / 1$ & $1 / 1$ & $0 / 0$ & $0 / 0$ & $1 / 1$ & $0 / 0$ & $0 / 0$ & $0 / 0$ \\
\hline \multicolumn{9}{|c|}{ Control } \\
\hline 1 & $0 / 0$ & $2 / 2$ & $0 / 0$ & $0 / 0$ & $1 / 1$ & $0 / 0$ & $0 / 0$ & $0 / 0$ \\
\hline 2 & $0 / 0$ & $2 / 2$ & $0 / 0$ & $0 / 0$ & $0 / 0$ & $0 / 0$ & $1 / 1$ & $0 / 0$ \\
\hline 3 & $0 / 0$ & $2 / 2$ & $0 / 0$ & $1 / 1$ & $1 / 1$ & $0 / 0$ & $0 / 0$ & $0 / 0$ \\
\hline 4 & $0 / 0$ & $2 / 2$ & $0 / 0$ & $1 / 1$ & $1 / 1$ & $0 / 0$ & $0 / 0$ & $0 / 0$ \\
\hline 5 & $0 / 0$ & $1 / 1$ & $0 / 0$ & $1 / 1$ & $0 / 0$ & $1 / 1$ & $0 / 0$ & $0 / 0$ \\
\hline
\end{tabular}

First pathologist/second pathologist (kappa=1) SC Schwann cell 

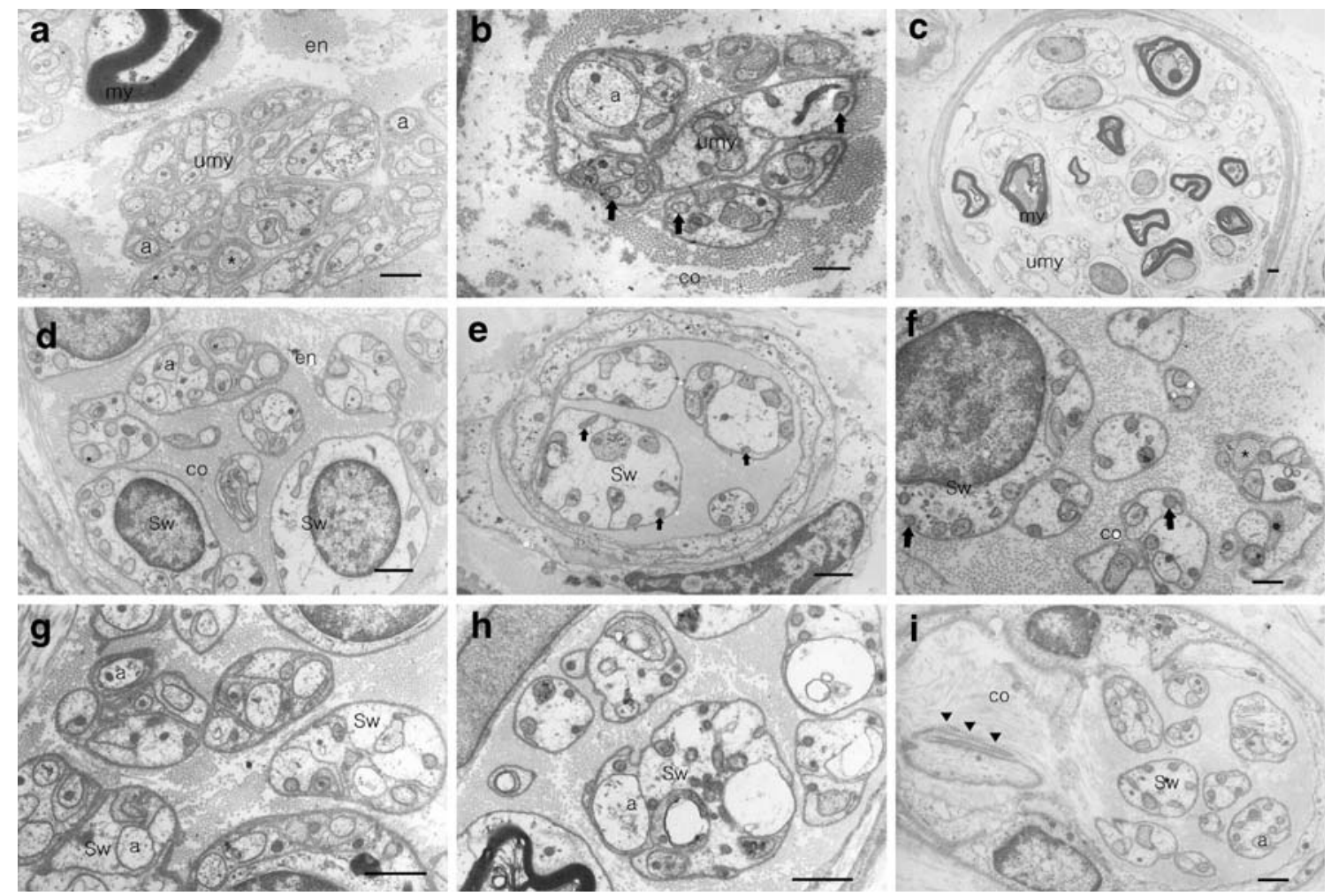

Fig. 1 Electron microscopic photographs taken from unmyelinated peripheral nerves in normal and fibromyalgia syndrome skin. a In normal skin, C-fiber (Remak) bundles of unmyelinated nerves (umy) near a myelinated nerve (my) show variegated sized axons $(a)$ sheathed well by complicatedly folded Schwann cell $(S w)$ membranes. Collagen pockets (asterisk) replacing axons are present. b In other normal skin, small axons (upward dark arrow) are present. c Low magnification photograph from FMS skin shows ballooned Schwann

cells and peripheralized small axons of Remak bundles. d Collagen fibrils (co) in endoneurium (en) are not less than normal controls (a and b). e A small nerve fiber shows small axons located in the peripheries of Schwann cells. f Collagen pockets are also present. $\mathbf{g}$ Non-tender area and $\mathbf{h}$ tender area show similar findings except more ballooned Schwann cells in tender areas. i Collagen crosslinking (arrow head) is noted near haphazard arranged collagen fibrils. $(\mathrm{bar}=1 \mu \mathrm{m})$

their unmyelinated Schwann cell sheaths. There is no report about these abnormalities of unmyelinated nerve fibers in other conditions including other chronic pain diseases. Two of the patients suffered from diabetes, and none of the control did suffer from that disease. Due to the extensive effect of diabetes on peripheral nerves, this point is worthy of mentioning. Swollen and vacuolated intraepidermal nerve fibers were identified in patients with neuropathy by conventional and immuno-electron microscopy in Lauria's study [16]. We do not think these abnormalities are tissue fixation artifacts or normal variation within human skin because there was no ballooning of Schwann cell in other myelinated fiber and we could see microtubules in axon.

These findings differ somewhat from previous EM studies of FMS [11, 15]. In Ribel-Madsen's study, skin biopsies were obtained from the thigh of 27 females who fulfilled the ACR criteria [1] of FMS and from eight control subjects who were matched for gender, age and physical activity. The overall microscopic picture was normal. The lamellar structure of the perineurium and a deficiency in collagen packing in the endoneurium was observed more frequently and to a larger extent in FMS patients than in controls [11]. In Sprott's study, highly ordered cuffs of collagen were observed around the terminal nerve fibers by EM examination of biopsy tissue from all eight patients with FMS, but were not observed in any of the control skin samples [15].

We noted collagen crosslinks which Sprott et al. [15] reported only in two cases of FMS. Unlike Ribel-Madsen et al.'s results, in which a deficiency in collagen packing in the endoneurium was observed more frequently and to a larger extent in FMS patients than in controls [11], collagen fibrils in endoneurium were not less than normal controls in our study (Fig. 1d). Despite these differences between our EM results and those of previous studies, these studies all suggest that there may be a number of identifiable abnormalities of the peripheral skin in FMS.

The meaning of these changes is unclear. The abnormalities that we identified could either be partly causing the increased pain sensitivity in FMS, or be due to it. For example, if FMS is primarily due to a decrease in the activity of descending, antinociceptive pathways in FMS patients [4], then peripheral nerves may depolarize more frequently because of the lack of inhibitory input in the dorsal horn, and 
could lead to such findings. In contrast, these changes could represent a fundamental problem in the peripheral nerves in FMS, and this could actually contribute to the increased pain sensitivity seen in this condition. In aggregate, these EM studies suggest that continued investigation of the peripheral nervous system may lead to useful insights into FMS.

The EM findings seen in the skin of FMS patients show unusual patterns of unmyelinated nerve fibers as well as associated Schwann cells. If these findings are replicated in a larger study, these abnormalities may contribute to, or be due to, the lower pain threshold seen in FMS patients.

Acknowledgement We acknowledge the assistance of Dr. Yoon Kyung Sohn with EM work.

\section{References}

1. Wolfe F, Smythe HA, Yunus MB et al (1990) The American College of Rheumatology 1990 criteria for the classification of fibromyalgia. Report of the Multicenter Criteria Committee. Arthritis Rheum 33:160-172

2. Clauw DJ (1995) The pathogenesis of chronic pain and fatigue syndromes, with special reference to fibromyalgia. Med Hypotheses 44:369-378

3. Gracely RH, Petzke F, Wolf JM et al (2002) Functional magnetic resonance imaging evidence of augmented pain processing in fibromyalgia. Arthritis Rheum 46(5):1333-1343

4. Juliena N, Goffauxb P, Arsenaultb P et al (2005) Widespread pain in fibromyalgia is related to a deficit of endogenous pain inhibition. Pain 114:295-302
5. Dadabhoy D, Clauw DJ (2005) Fibromyalgia: progress in diagnosis and treatment. Curr Pain Headache Rep 9(6):399-404

6. Granges G, Littlejohn G (1993) Pressure pain threshold in painfree subjects, in patients with chronic regional pain syndromes, and in patients with fibromyalgia syndrome. Arthritis Rheum 36:642-646

7. Aaron LA, Burke MM, Buchwald D (2000) Overlapping conditions among patients with chronic fatigue syndrome, fibromyalgia, and temporomandibular disorder. Arch Intern Med 160:221-227

8. Simms RW (1996) Is there muscle pathology in fibromyalgia syndrome? Rheum Dis Clin North Am 22:245-266

9. Sprott H, Salemi S, Gay RE et al (2004) Increased DNA fragmentation and ultrastructural changes in fibromyalgic muscle fibres. Ann Rheum Dis 63(3):245-251

10. Kim SH, Jang TJ, Moon IS (2006) Increased expression of NMethyl-D-Aspartate Receptor Subunit 2D in the skin of patients with fibromyalgia. J Rheumatol 33:785-788

11. Ribel-Madsen S, Gronemann ST, Bartels EM et al (2005) Collagen structure in skin from fibromyalgia patients. Int J Tissue React 27(3):75-82

12. Littlejohn GO, Weinstein C, Helme RD (1987) Increased neurogenic inflammation in fibrositis syndrome. J Rheumatol 14 (5):1022-1025

13. Enestrom S, Bengtsson A, Frodin T (1997) Dermal IgG deposits and increase of mast cells in patients with fibromyalgia-relevant findings or epiphenomena? Scand J Rheumatol 26(4):308-313

14. Salemi S, Rethage J, Wollina U et al (2003) Detection of interleukin $1 \beta$ (IL-1 $\beta$ ), IL-6, and tumor necrosis factor- $\alpha$ in skin of patients with fibromyalgia. J Rheumatol 30:146-150

15. Sprott H, Muller A, Heine H (1997) Collagen crosslinks in fibromyalgia. Arthritis Rheum 40(8):1450-1454

16. Lauria G, Morbin M, Lombardi R et al (2003) Axonal swellings predict the degeneration of epidermal nerve fibers in painful neuropathies. Neurology 61:631-636 